\title{
ANTROPOLOGICAL ELEMENTS IN THE IMPLANT-PROSTHETIC REHABILITATION
}

\section{Kozma Andreï', Forna Norina²}

',Alessandrescu Rusescu” National Institute for Mother and Child Health, Bucureşti

${ }^{2}$ „Grigore T. Popa” University of Medicine and Pharmacy, Iasi

Andrei Kozma

\begin{abstract}
The dental anthropology can bring various contributions in the assessment of the pathology of the stomatognathic system as this field encompasses the genetic and clinical researches focused on the developmental defects of crowns, post-eruptive changes (dental wear, culturally-related dental changes) as well as patterns of teeth loss. The implant-prosthetic rehabilitation is highly recomended for these patients as having the highest rate of success in the therapy of the stomatognathic system disorders. The anthropological elements related to the optimisation of the implant-prosthetic rehabilitation of the stomatognathic system are related to the anatomical and morphological featires of prosthetic field, the favourable and non-favourable areas of the prosthetic field, the type and the orientation of the traction and pressure masticatory forces as well as the lamina dura preservation when edentation is associated to periodontal disease.
\end{abstract}

Keywords: anthropology, dental implant, prosthetic rehabilitation

The science of anthropology can elucidate, using advanced techniques and research methodologies, the changes of the oral cavity components, due to changes in nutritional status, social and economic factors, people migrations, as well as marriage between people from different geographic regions (1).

Anthropological researchers have reached the ability to perform studies that address both to molecular and phenotypic areas, and thus they can explain issues related to the normal and abnormal development of dentition, as well as the pathology related to the partial and total edentation (1). Also a deeper understanding of cultural anthropology is essential for every clinician, so as to trace the possible aetiology of a disease to one's cultural habits (2).

The dental anthropology can bring various contributions in the assessment of the pathology of the stomatognathic system as this field encompasses the genetic and clinical researches focused on the developmental defects of crowns, post-eruptive changes (dental wear, culturally-related dental changes) as well as patterns of teeth loss (3).

The anthropological studies highlighted the fact that teeth exhibit morphological and metrical parameters that vary within the same population as well as between different populations. These variations conduct to a broad range of 
stomatognathic system features that can influence the approach of the prosthetic treatment planning of the edentulous patients. Scott\&Turner (2004) divided the morphological variants that are related to disorders of the stomatognathic system in one type that involve major deviations from the basic blueprint, including hypodontia, supernumerary teeth, fused teeth, and a second dental variation consisting of minor variations in secondary cusps, supernumerary cusps, fissure patterns, accessory ridges, marginal ridges, supernumerary tooth, variations in curves and angles of the coronal morphology (3). For both categories, the major factors of the idiosyncratic dental anomalies are mostly environmental factors during teeth development (3). While large deviations from the normal patterns are functionally deleterious, minor variations of the dental morphology are also related to occlusal, muscular and articular disorders of the stomatognathic system (3).

A general pattern for the loss of teeth consists of the loss of mandibular molars, starting from adulthood, followed by maxillary molars, maxillary premolars, mandibular premolars and, frequently, maxillary incisives. Generally, 70\%$75 \%$ of patients have extended partial edentation after age 55 (4). Also $75 \%-80 \%$ of patients have bimaxillary class I Kennedy edentations at age 5055 (4). The importance of the prosthetic treatment when the disorders of the stomatognathic system are diagnosed is highlighted by the researches that demonstrated that partial extended edentation is associated to the decrease of systemic status and the life expectancy. The loss of all molars reduces the life expectancy with $60 \%-70 \%$ (4). The mortality increases significantly within patients with subtotal and total edentation. In this context, a high percent of population will adress to the dentists for complex oral rehabilitation. Implantprosthetic rehabilitation is highly recomended for these patients as having the highest rate of success in the therapy of the stomatognathic system disorders (5).

The development of the formation and functioning of the stomatognathic system is progressing from birth to age 12 when a definitive model is completed. This model must be respected by the prosthetic specialist during the therapy of edentulous patients (5). Also to ensure the success of the prosthetic therapy in-depth knowledge of the anatomical and morphological elements of the prosthetic field is requested as well as the paraclinical investigations by ortopantomography and cone-beam computertomography. The proper assessment of the morphology and structure of the alveolar crest for edentulous patients is important to differentiate the favourable bone sites from unfavorable areas for the dental implants insertion. The prosthetic or implant-prosthetic restorations will rehabilitate the occlusal relationships and will ensure the removal of the occlusal trauma and muscular and articular disorders. Other anthropological elements related to the recommendations for the implant-prosthetic rehabilitation of the stomatognathic system are as follows (5):

-in the case of maxillary edentation, the intrabone area of the dental implants must be inserted in the non-resorbable palatal spongious bone area;

- in the frontal maxillary edentation, the apex of the dental implants can be introduced in the dense bone cortical area for better primary implant stability;

- in the case of the non-resorbed maxillary bone area, osteointegrated implants can be inserted;

- in the posterior maxillary edentation the sinus mucosa can induce high resorption of the sinusal floor; sinus lift associated with guided bone regeneration is requested due to the fact that the thin bone layer can be easy perforated during the implant;

- for the mandibular extended partial edentation or in the case of total edentulous patients, subperiostal implants are recommended associated with alveolar augmentation procedures;

- for the cases with edentation associated to severe periodontal disease, with unregularized resoption of lamina dura, it is recommended the avoiding of lamina dura perforation to avoid new traction forces that could modify the regional trabecula system; the respect of lamina dura will increase the primary stability of the implant and will accelerate the bone healing;

- the favorable areas for implant treatment include the region of primary maxillary molars due to the dense spongious bone 
tissue surrounded by hard bone tissue reinforced by the transmission masticatory pression-traction forces from lamina dura to intrabone trabeculation; regiunea mentonieră, între cele 2 găuri mentoniere, este o regiune favorabilã inserţiei implanturilor;

-posterior mandibular area is favourable for implantation when the height of restant bone tissue is minimum $8 \mathrm{~mm}$ over mandibular canal and the bone thick is minimum $6 \mathrm{~mm}$; when the height is under $4 \mathrm{~mm}$ alveolar augmentation procedures are requested.

The assessment of normal or pathological aspects of the dental occlusion requests the analysis of the relations between mandibular condyle and glenoid articular surface, in static and dynamic dental articulations. Regarding the functional disorders of the stomatognathic system, the anthropology can also analyse the changes of the relationships between maxillary and mandibule arcades and dental occlusion by assessing the changes related to the temporomandibular joint (TMJ), the synovial articulation between the temporal bone of the skull and the mandible. This relation is important for the proper functioning of the stomatognathic system as right and left TMJ act together and every change of one TMJ will provoke functional disorders to the other joint as well as to the occlusal relationships and muscles of the stomatognathic system (6).

The mastication influences the oral health as well as the mental and spiritual human functions (7). The presence of primary and secondary permanent molars has a major importance in the formation of the masticatory „voluntary mechanical automatism" that is modelling between age 6 and age 12, and is completed in the same time with the formation of the masticatory cycle related to the form and dentition occlusal patterns. The mastication effectiveness can be reduced starting from age 6 and 12, in relation to the absence of primary or secondary definitive molars. Every absence of these molars will influence the occlusion and dental articulation, due to the disorders of the static and dynamic relation between articular condyle, articular meniscus and articular tubercle (7).
Anthropological researchers were always interested in the relation between teeth and human beauty, as the integrity of alveolar arcades influences not only the effectiveness of speech, mastication and deglutition but also the esthetics. The loss of anterior maxillary and manibular teeth, due to rampant caries, periodontal disease, or trauma, is associated to major esthetic disorders, social isolation tendency, as well as the lack of vitality, will, kindness, and even mental disorders. The oral complex rehabilitation (especially implant-prosthetic rehabilitation) represents an effective approach for the resolution of the anxiety and depressive states, as well as for their social reinsertion (7). However the preventive strategies are desirable, considering the high prevalence of the edentation in Romania as well as the challenges of the prosthetic treatment for people with poor economic status (8), (9), (10). The assessment of the social and biological parameters will support an oral diagnosis with high predictability (11).

\section{Conclusion:}

The anthropology can contribute to the oral complex rehabilitation along with others fields of the dental medicine (dental prosthetic, implantology, oral surgery, periodontology, restorative dentistry) aiming to reestablish both the biological functions (mastication, deglutition) and psycho-social functions (speech, esthetics).

\section{References}

1. Townsend G, Bockmann M, Hughes $T$, Mihailidis S, Seow WK, Brook A. New approaches to dental anthropology based on the study of twins. In: Townsend G, Kanazawa E, Takayama H, editors. New Directions in Dental Anthropology: Paradigms, Methodologies and Outcomes. The University of Adelaide Press; 2012. p. 10-21.

2. Swati Jain, Basavaraj Patthi. Cultural_ anthropology_and_its_effect_on_oral_ health. ; Photon eBooks, $2014: 4 \overline{7}$

3. Scott GR, Turner CG. The Anthropology of Modern Human Teeth: Dental Morphology and Its Variation in recent human populations. 
Cambridge Press, 2004.

4. Firu, P., Apostolescu S. Asistenţa şi învăţământul de medicină dentară din trecut până în prezent. Ed. Junimea, Iaşi, 2006.

5. Forna N, Firu P. Introducere în antropologia medicalã dentarã. Iasi: Casa Editorialã Demiurg, 2013.

6. Forna N \&col. Protetica dentară vol.I,II. Editura Enciclopedica, 2011.

7. Firu P, Forna N- Dinţii în antropologia medicalã dentarã, Iasi, 2012.

8. Antohe-Ecaterina Magda, Andronache Monica, Feier Ramona, Stamatin Ovidiu, Forna Consuela Norina. Statistical studies regarding therapeutic approaches for edentulous social clinical cases in students practical stages. Romanian Journal of Oral Rehabilitation Vol. 9, No. 2, April June 2017: 94-99.

9. Antohe-Ecaterina Magda, Stamatin Ovidiu, Feier Diana Ramona, Andronache Monica, Forna Norina. Clinical and technological rehabilitation of partial edentation complications. Romanian Journal of Oral Rehabilitation Vol. 9, No. 4 OctoberDecember 2017: 84-89.
10. Magda Ecaterina Antohe, Monica Andronache, Ramona Feier, Ovidiu Stamatin, Norina-Consuela Forna. Aspects of oral rehabilitation using removable dentures: esthetics and functionality. Romanian Journal of Oral Rehabilitation. Vol. 10, No. 1, January - March 2018: 133-139.

11. Frăţilă Dragoş, Scutariu Monica Mihaela, Forna Norina. Clinical and paraclinical indicators in the establishment of an oral diagnosis with high predictability. Romanian Journal of Oral Rehabilitation. Vol. 6, No. 2, April - June 2014: 100-105. 